\title{
Het Nederlands Historisch Instituut te Rome: Enige beschouwingen en suggesties
}

In de eerste aflevering van BMGN werd in Een woord ter inleiding geconstateerd, dat er in de Nederlandse historische wereld nog maar weinig debat gevoerd wordt. In diezelfde aflevering werd in de kroniek melding gemaakt van het verschijnen van de Nota van de sectie geschiedenis van de Academische raad over de beoefening van de wetenschap der geschiedenis in Nederland, waarbij tot slot de hoop werd uitgesproken, dat deze^nota de kritische aandacht krijgt, die zij verdient. Nu is het niet mijn bedoeling te discussieren over de nota, tenzij ik dienaangaande als fundamenteel manco wil gaan constateren, dat in paragraaf 3.1.3., waar gesproken wordt over internationale contacten, geen melding wordt gemaakt van het Nederlands Historisch Instituut te Rome. Dit zou echter als kritiek op de nota niet diep snijden, want door het niet vermelden van dit instituut heeft de redactiecommissie, zij het wellicht onbewust en in het volstrekt negatieve, de situatie in de betrekkingen tussen de Nederlandse historici en de Romeinse instelling heel raak getekend. Het instituut te Rome speelt nauwelijks een rol in de Nederlandse geschiedbeoefening. Hierdoor ontstaat de merkwaardige toestand, dat het veeleer te kampen heeft met een gebrek aan nationale, dan aan internationale contacten. Zo men hier kritiek wil uiten, dan zou die zich moeten richten op de Nederlandse historische wereld als geheel.

Dat er hier sprake is van een niet optimaal functioneren van een in potentie belangrijk hulpmiddel ten behoeve van de wetenschap der geschiedenis in Nederland, lijkt mij onbetwistbaar maar vooral betreurenswaardig, omdat de instelling te Rome het enige historische instituut in het buitenland is, dat ons land zich permitteert. Nu kan men het belang ervan relativeren door te beweren, dat het beter elders had kunnen staan. Dit is op de eerste plaats vruchteloos gepraat achteraf, dat vervolgens blijk geeft van niet op de hoogte te zijn met de situatie te Rome en met de argumenten, waarom een hele reeks landen aldaar instituten hebben opgericht. Wij waren beslist niet de eersten; wie had ook anders verwacht.

Inmiddels is door het oprichten van zoveel instituten te Rome een unieke situatie ontstaan: nergens ter wereld doet zich een dergelijke concentratie aan buitenlandse historische instituten voor. Aanleiding hiertoe was in de meeste gevallen de openstelling van het Vaticaans archief in 1883, maar daarnaast bieden de stad Rome en Italië een zodanige rijkdom aan bibliotheken en aan andere mogelijkheden tot emplooi voor historici, dat ook andere argumenten golden. De concentratie van buitenlandse instituten werkt bovendien cumulatief ten aanzien van de bestaansgronden ervan. Behalve historici zijn ook grote aantallen kunsthistorici op Rome en zijn heerlijkheden afgekomen, om over de archeologen nog te zwijgen. Zo verrezen er eveneens kunsthistorische en archeologische instituten of speciaal op deze disciplines gerichte afdelingen aan de bestaande instituten. Bijgevolg gonst de stad van buitenlandse geleerdheid en internationale bedrijvigheid in wetenschappen, die speciaal te Rome onderling zo nauw gelieerd zijn. Men dient daarbij nog voor ogen te houden, dat Rome de hoofdstad is van een land met een indrukwekkend cultuurbezit en dat vanuit Rome exploraties over geheel Italië kunnen worden opgezet. 


\section{P. VAN KESSEL}

Al heeft Nederland dan vanaf 1904 zijn instituut te Rome, helaas moet men voor ons, ook in verhouding tot andere relatief kleine landen zoals Oostenrijk en België, een vrij geringe interesse voor dit kostbare gegeven constateren. Vergelijkenderwijs zou men zelfs van een achterstand kunnen spreken. Om dit te beseffen, behoeft men alleen maar de series publicaties van de verschillende buitenlandse instituten in Rome na te gaan. Hieruit blijkt tevens, dat andere landen veelal op een veel sterkere Italiaans-gerichte traditie kunnen steunen. Nederland beschikt in dit opzicht over weinig reserves en die zijn ook niet op korte termijn te creëren. Er zal een traditie moeten worden gekweekt en daar gaat minstens een generatie overheen. Heeft het eigen instituut te Rome hier gefaald? Men zou hoogstens kunnen zeggen, dat een te sterk personalistische aanpak ervan - overigens karakteristiek voor de periode tussen de wereldoorlogen - te weinig bedacht is geweest op planning met het oog op continuïteit en toekomst. Maar is het maken van verwijten al een onvruchtbare bezigheid, men zal vooral goed moeten benadrukken, dat het instituut een product is en blijft van de historici, c.q. kunsthistorici en archeologen in Nederland. Het instituut kan zelf stimuleren, luisteren en suggesties doen, maar wanneer het op uitvoeren aankomt, zal het moeten drijven op de aanvoer uit Nederland.

Om bovenstaande beweringen nader te adstrueren en uit te werken en om een soort balans op te maken, heb ik een Overzicht samengesteld van de belangrijkste verrichtingen van het Nederlands Historisch Instituut te Rome en van die der andere buitenlandse instituten aldaar op het gebied van de geschiedenis. Het is de bedoeling, dat dit in 1971 nog zal verschijnen in de Mededelingen van het Nederlands Historisch Instituut te Rome, deel $\mathrm{XXXV}$. Het is geschreven om gecompleteerd te worden door een korte omschrijving van de huidige situatie en een prognose omtrent mogelijkheden in de toekomst. Deze volgen hier.

Alvorens over te gaan tot een puntsgewijze behandeling van heden en toekomst van het instituut, wil ik nog even stilstaan bij de vraag, hoe het komt dat de Nederlandse historici relatief zo weinig aandacht hebben besteed aan de Romeinse instelling. Datzelfde geldt overigens ook voor Rome, Italië en Zuid-Europa in het algemeen; in dit opzicht kan men spreken van een manco in onze historiografie. Ongetwijfeld bestaat er verband tussen deze twee kwesties. Antwoord erop geven is uitermate moeilijk en gevaarlijk wegens de dreiging van onjuiste generalisering. Men kan wel met enige grond stellen, dat de zwakke presentie van de Nederlandse geschiedwetenschap te Rome verband houdt met hetgeen de nota in het algemeen constateert: een achterstand in aantallen studenten in de geschiedenis en vakhistorici ten opzichte van andere wetenschappen, alsmede een gebrek aan organisatorische aanpak en institutionalisering. Het komt mij echter voor, dat er daarnaast sprake is van zekere remmingen van cultuurhistorische oorsprong juist ten aanzien van Zuid-Europa, althans, wanneer het gaat om een serieuze en wetenschappelijke evaluatie. Mogelijk dat ook een overmaat aan filologisch-humanistische ingetogenheid in onze historiografie enigszins belemmerend werkt, wanneer het gaat om culturen, waar pracht en praal, theater en festijn, maar dan ook dramatiek en tragedie een belangrijke plaats innemen. Het vraagstuk is beslist interessant en leent zich ook voor historische reflecties, maar men doet er niet goed aan de oplossing ervan als voorwaarde te stellen voor het ontwikkelen van intenser activiteit op het gebied van Zuideuropese geschiedenis; integendeel.

Na deze algemene inleiding, nu de zaak zelf. 


\section{DE ALGEMENE SITUATIE AAN HET INSTITUUT TE ROME MET BETREKKING TOT DE HISTORISCHE AFDELING}

\section{A. De oorspronkelijke opzet}

1. Het instituut werd opgericht in 1904 op instigatie van P. J. Blok en Gisbert Brom. Eerste doel was systematisch onderzoek in de Vaticaanse en Romeinse archieven en bibliotheken naar zaken van belang voor de geschiedenis van Nederland. De hieruit voortvloeiende publikaties stonden onder supervisie van de commissie van advies voor de Rijks Geschiedkundige Publicatiën.

In de eerste jaren was de activiteit gericht op algemene inventarisering van de vindplaatsen. Zo verscheen de serie Archivalia in Italië belangrijk voor de geschiedenis vanNederland (RGP, kleine serie ns. 2, 6, 9 en 14) en daaraan parallel de serie Bescheiden in Italië omtrent Nederlandsche kunstenaars en geleerden (RGP, kleine serie, ns. 10, 12 en 17).

Hierna richtte men zich op een systematische uitgave van speciale archieffondsen volgens de ns. 15 en 48 uit het Overzicht van de door bronnenpublicaties aan te vullen leemten der Nederlandsche geschiedkennis, het werkprogram van de RGP uit 1904. Zo ontstonden de series Romeinse bronnen (RGP, grote serie, ns. 52,77, 84,94 en 97) en Romeinse bescheiden (RGP, grote serie, ns. 103 en 110). Aan deze laatste serie wordt momenteel verder gewerkt.

2. In de loop der jaren groeide uit het kunsthistorisch onderzoek een zelfstandige kunsthistorische afdeling, met name onder G. J. Hoogewerff. Tijdens diens directoraat was deze kunsthistorische activiteit toonaangevend voor het gehele Historische Instituut. De banden met. dei RGP versmalden zich relatief tot de historische uitgaven. Het instituut startte met een eigen tijdschrift, de Mededelingen, en met een eigen serie Studiën.

In 1920 werd een archeoloog aan het instituut verbonden in de persoon van H. M. R. Leopold. Zo ontstond een derde afdeling. Deze drie afdelingen verkregen een hoge mate van autonomie wat hun wetenschappelijke activiteiten aangaat. Hieronder zal slechts aandacht worden besteed aan kwesties de historische afdeling betreffend, alhoewel veel ervan ook voor de andere afdelingen kan gelden. Geheel buiten beschouwing is gelaten, wat het instituut voor andere disciplines kan betekenen.

\section{B. Bestaande mogelijkheden, middelen en doelstellingen}

1. Mogelijkheden en middelen

a. De historische afdeling bestaat uit één wetenschappelijk ambtenaar, die tevens afdelingshoofd is.

b. Het ministerie van Cultuur, Recreatie en Maatschappelijk werk, waaronder het instituut ressorteert, verleent jaarlijks een achttal stipendia, te verdelen over de drie afdelingen.

c. Het instituut beschikt over een bibliotheek, gericht op de drie afdelingen. De historische afdeling legt zich speciaal toe op de Nederlandse geschiedenis en geschiedschrijving ter aanvulling van hetgeen in andere bibliotheken en instituten te Rome aanwezig is.

d. Het instituut heeft een eigen tijdschrift, de Mededelingen.

e. Daarnaast is er een serie Studiën, sinds 1965 voor elke afdeling afzonderlijk. 


\section{P. VAN KESSEL}

\section{Doelstellingen}

a. Het uitvoeren van eigen onderzoek. In casu het voortzetten van de Romeinse bescheiden in het kader van de RGP.

b. Studiebegeleiding van de stipendiaten. Deze kunnen meestal onderdak vinden in het instituut tegen zeer gunstige voorwaarden.

c. Hulp aan Nederlandse historici. Dit omvat bestellen van fotocopieën of maken van afschriften, verzamelen van bio- en bibliografische gegevens, verstrekken van inlichtingen en adviezen, maken van afspraken enz.

d. Het verstrekken van wetenschappelijke informaties aan Italiaanse en andere nietNederlandse historici en geïnteresseerden.

e. Het redigeren van de Mededelingen en de Studiën voorzover dit de geschiedenis betreft.

f. Het onderhouden in het algemeen van contacten met de historische wereld in Nederland en met de collega-instituten te Rome.

\section{OVERZICHT VAN DE BELANGRDKSTE PROBLEMEN EN DESIDERATA}

A. Zoals in de inleiding is geconstateerd, blijkt het instituut te Rome niet optimaal te functioneren in de Nederlandse geschiedbeoefening. Een van de oorzaken hiervan zou men de beperktheid van het instituutsonderzoek kunnen noemen, ofschoon dit evengoed gevolg kan zijn. Er is hier sprake van een vicieuze cirkel. Deze zou doorbroken moeten worden door het opzetten van meerdere en gevarieerde instituutsprojecten, teneinde de interesse en vooral de mogelijkheden tot participatie te vergroten.

B. Aangezien een belangrijk deel van de geschiedbeoefening plaats vindt aan de universiteiten, zal het contact tussen universitaire wereld en instituut geïntensiveerd moeten worden. De laatste jaren is hierin reeds verbetering opgetreden ten gevolge van de stipendia, waardoor geregeld candidaten of doctorandi in het instituut kwamen. De relaties zijn echter nog steeds beperkt en vooral te toevallig. Ook hier zou uitbreiding van het instituutsonderzoek verbetering kunnen brengen, doordat organische betrekkingen worden aangeknoopt.

C. Temidden van de andere buitenlandse instituten te Rome, ook van de kleinere naties, neemt het Nederlandse als researchcentrum een tamelijk bescheiden plaats in, geheel evenredig aan de beperktheid van het eigen onderzoek, maar ook als gevolg van het typisch nationale karakter ervan. Bij het verruimen van het instituutsonderzoek zou men er goed aan doen deze grens te doorbreken.

D. Ter bevordering van de internationale contacten, waartoe Rome door de aanwezigheid van zoveel buitenlandse instituten uitzonderlijke gelegenheid biedt, zou men van Nederlandse zijde bereid moeten zijn deel te nemen aan internationale ondernemingen. Juist de laatste tijd nemen plannen daartoe concretere vormen aan en het zou te betreuren zijn, indien Nederland verstek zou laten gaan.

E. Verruiming en internationalisering van het instituutsonderzoek zouden de mogelijkheden tot werkelijke studiebegeleiding van de stipendiaten vergroten. Zij zouden desgewenst kunnen meewerken aan de projecten. Zelfs inschakeling bij projecten van andere instituten lijkt geen utopie.

F. Tenslotte mag in overweging worden genomen, dat de huidige investeringen en de kosten voor materiële instandhouding van het instituut een hoger rendement zullen op- 
HET NEDERLANDS HISTORISCH INSTITUUT TE ROME

leveren bij een intenser gebruik. Analoge overwegingen kunnen ook gelden ten aanzien van de instituutspublikaties.

\section{ENIGE MOGELIJKHEDEN TOT UITBREIDING VAN DE INSTITUUTSRESEARCH}

\section{Opmerkingen vooraf}

1. Een wetenschappelijk instituut bedoelt meer te zijn dan een gebouw, waarin een willekeurig samengesteld gezelschap op comfortabele wijze individuele onderzoekingen verricht vanuit persoonlijke interesses; het dient zich te richten op zaken, die de individuele spankracht te boven gaan. Zo zal een instituutsprogram verder moeten reiken dan de som van de bezigheden der medewerkers. Dit beginsel hoeft niet allen uit het instituut te weren, die er komen vanwege eigen studies. Ook moet de medewerkers gelegenheid gelaten worden tot eigen onderzoek. Er is een vruchtbare combinatie denkbaar van algemeen en privébelang, van planning van bovenaf en privé-initiatief.

2. Het Romeinse instituut houdt zich krachtens traditie in de eerste plaats bezig met het uitgeven van bronnen. In de discussies tussen medewerkers aan de verschillende buitenlandse instituten te Rome valt de laatste tijd echter enig onbehagen dienaangaande te constateren. Ik meen dat als volgt te kunnen samenvatten:

a. Programma's, opgesteld omstreeks 1900, lijken heden product van positivistische zelfoverschatting, temeer omdat verfijnder methodieken en hogere eisen het uitgeven van bronnen gecompliceerder en bewerkelijker maken, tenzij men geheel andere wegen gaat bewandelen.

b. Vaak zijn de eenvoudig te ontginnen terreinen bewerkt en wordt men nu voor moeilijker opgaven geplaatst, zoals toenemend briefverkeer in de achttiende en negentiende eeuw en gecompliceerder of minder geordend maar wel vollediger bewaarde archiefcomponenten.

c. Uitgebreider toepassing van de fotografie blijkt geen afdoende compensatie voor het uitsterven van het 'ras' van afschrijvers en de toenemende eisen van de kant van de drukkers ten aanzien van het 'manuscript'.

d. De behoefte aan 'structurele geschiedenis' ondergraaft het geloof in de edities die zich voornamelijk op diplomatieke geschiedenis richten; alternatieven zijn echter moeilijk te bieden.

e. De belasting, veroorzaakt door de oude programma's, laat weinig gelegenheid voor de toenemende interesse voor de nieuwste geschiedenis.

f. De toenemende systematisering van de universitaire carrière en de eis van specialisering ontnemen aan de archiefbewerker alternatieve toekomstmogelijkheden; dit in tegenstelling tot een vroegere situatie, toen organisatorische koppeling aan een universiteit minder voorwaarde was voor een roulering.

3. Naast het uitgeven van bronnen zou het bewerken van bepaalde periodes d.m.v. monografische studies heel wel tot een instituutsprogramma kunnen behoren.

\section{Concrete voorstellen}

Bij het opstellen van deze lijst is een centrale plaats gegeven aan het Vaticaans archief en de Vaticaanse bibliotheek. Deze twee instellingen vormen, ook krachtens traditie, het centrum voor de historische research te Rome door de buitenlandse instituten. Wanneer 


\section{P. VAN KESSEL}

men niet van deze basis uitgaat, loopt men het gevaar internationaal bezien geïsoleerd te raken, zeker wanneer men, zoals dat voor ons het geval is, zo weinig ervaring heeft met andere operatie-gebieden. Het is echter duidelijk, dat men niet bij de basis hoeft te blijven stilstaan.

Vervolgens is deze lijst samengesteld op grond van ervaringen en inzichten, te Rome verworven; er ontbreekt, om het zo te zeggen, het wederwoord uit Nederland. Aanvullingen, suggesties en opmerkingen kunnen bijdragen tot vruchtbare discussie.

\section{A. Middeleeuwen}

1. Voortzetting van het Corpus Vaticano-Burgundicum, een onderneming in de trant van het Repertorium Germanicum, opgezet vanuit Groningen.

2. Bewerking van de Vaticaanse en Romeinse bibliotheken in het kader van een Corpus Auctorum Scholasticorum Neerlandicorum Medii Aevi (zie Drie rapporten over de uitgave van bronnen voor de Nederlandse geschiedenis, uitgegeven door de Rijkscommissie voor Vaderlandse Geschiedenis, 's-Gravenhage, 1952, p. 39).

N.B. Beide werkzaamheden lijken bij uitstek geschikt om te worden uitgevoerd in Benelux-verband. Ten aanzien van het tweede punt schijnen te Nijmegen en Brussel initiatieven te bestaan.

\section{B. Moderne geschiedenis}

1. Voortzetting van de Romeinse Bescheiden, waarvan deel III tot 1814 op stapel staat. Het ligt voor de hand, dat er na de Romeinse Bronnen tot 1727 en de Romeinse Bescheiden tot 1853 zoiets zal komen als Romeinse Paperassen tot 1909, aangezien het argument voor de twee eerste series, het ressorteren van de Katholieke Kerk onder de Congregatie De Propaganda Fide, tot dat jaar blijft gelden.

2. Bewerking van de Romeinse, eventueel Italiaanse bibliotheken in het kader van een Corpus Philosophorum Neerlandicorum (zie Drie rapporten ... p. 44). Een dergelijk project zou tevens aansluiten bij hetgeen vroeger door het instituut is gedaan met betrekking tot Nederlandse geleerden in Italië (zie Bescheiden omtrent Nederlandsche kunstenaars en geleerden in Italië en de Mededelingen, passim). Op dit gebied liggen ook mogelijkheden voor classici. Men zou vervolgens contact kunnen zoeken met de Archives Internationales d'Histoire des Idees.

3. Bewerking van het Fondo Paci in het Vaticaans archief, te weten de collectie documenten'betreffende de grote Europese vredesonderhandelingen uit de zeventiende en achttiende eeuw. Dit onderzoek zou prachtig aansluiten op wat andere Romeinse instituten doen aan Nuntiatuurberichten. Een plan tot bewerking van dit archieffonds is indertijd reeds voorgesteld door Von Pastor als directeur van het Oostenrijkse Historische Instituut te Rome. Dit laat echter geen claim gelden en bleek, evenals andere buitenlandse instituten, wel te voelen voor een internationale aanpak. Men zou tevens contact kunnen opnemen met de bewerkers van de Acta Pacis Westphalicae.

4. Bewerking in monografieën van de Kerkelijke Staat rond 1600. De keuze 1600 houdt verband met de curieuze toestand van een pausschap dat enerzijds door de reformatie in belangrijke mate aan invloed heeft ingeboet, maar anderzijds in het barokke Rome een hoogtepunt creëert.

Men zou hier kunnen experimenteren met een 'structurele' aanpak. Om de gedachten nader te bepalen, men zou studies kunnen projecteren als: Verhouding tussen pauselijk be- 


\section{HET NEDERLANDS HISTORISCH INSTITUUT TE ROME}

beleid en curiale invloed; Eer en hoogheid der curiale functies; Opleiding en onderricht in de Kerkelijke Staat; Bronnen van inkomsten in de Kerkelijke Staat; Verhouding stad en platteland; Verhouding Kerk-Staat in de Kerkelijke Staat; Doorwerking van Trente in de wetgeving.

De theocratisch-absolutistische bestuursvorm van de Kerkelijke Staat levert uniek materiaal voor sociologische, cultuur-psychologische benaderingen. Men dient daarbij te bedenken, dat de geschiedenis van de Kerkelijke Staat en van de curie tot nu toe in de schaduw is blijven staan van die der pausen.

5. Venetië. Voortzetting van de Capita Selecta Veneto-Belgica (Studiën van het Nederlands Historisch Instituut te Rome, IV). Daarnaast zouden oók monografische en vergelijkende studies over Nederlands-Venetiaanse zaken denkbaar zijn. Venetie heeft daarom ook veel aantrekkelijks, omdat de gemeente alle faciliteiten biedt aan buitenlandse instellingen, met als gevolg een toenemende internationalisering van deze boeiende stad. Voor historici is er tevens de unieke collectie microfilms van de Fondazione Cini, die het mogelijk maakt te Venetië de belangrijkste archiefseries uit heel Europa te consulteren.

\section{Nieuwste geschiedenis}

De mogelijkheid van bronnenpublikaties is hier gering. Aangewezen lijkt hier monografische behandeling van kwesties als:

1. De opkomst van de politieke partijen in Italië.

2. Liberalisme, socialisme en katholiek integralisme rond 1900.

?. Het anarchisme in Italië.

4. De politieke partijen en het fascisme.

5. Het Italiaanse kolonialisme.

6. Van koninkrijk naar republiek.

7. Privé- en staatsondernemingen.

8. Beleggingsactiviteiten.

9. Italiaanse belastingpolitiek.

Dit is maar een greep uit een reeks mogelijkheden. Het is duidelijk dat dergelijke studies veelal slechts oriënterend zullen zijn.

\section{ENIGE OVERWEGINGEN VAN ORGANISATORISCHE AARD}

\section{A. Het wetenschappelijkwerk}

1. Planning van en toezicht op de uitgave van bronnen kan het best berusten bij een algemeen overkoepelende instantie in Nederland, bijvoorbeeld de Rijkscommissie voor Vaderlandse Geschiedenis, waarmee het Instituut via de RGP uitgaven 'historische' banden heeft.

2. Monografische studies zullen veelal tevens dissertaties zijn. Het toezicht berust dan automatisch bij de promotores. Hier blijkt duidelijk hoe de integratie van het instituut in de universitaire wereld gewenst is.

\section{B. Uitvoerders van het wetenschappelijk werk}

1. Ideaal lijkt aanstelling van medewerkers voor een periode overeenkomstig het uit te 


\section{P. VAN KESSEL}

voeren project of deel van een project. Dit is slechts mogelijk bij een integratie van het instituut in een systeem, dat roulering mogelijk maakt. Wederom lijkt hier integratie in het universitaire bestel de aangewezen weg.

2. Via deze integratie zullen er ook meer mogelijkheden bestaan voor het inschakelen van stipendiaten bij de instituutsresearch.

3. Er zou gezocht kunnen worden naar het scheppen van faciliteiten voor hoogleraren, lectoren, wetenschappelijke medewerkers en leraren, om voor studie langere tijd in Rome te verblijven (sabbatical year).

\section{Didaktische taak van het Instituut}

1. Naast de begeleiding van de instituutsstipendiaten zou men hun algemenere cursussen over Romeinse of Italiaanse aangelegenheden kunnen bieden.

2. Het instituut zou, in overleg met organisaties en instanties in Nederland, zomercursussen kunnen organiseren voor studenten of afgestudeerden (postgraduate studies).

\section{Besluit}

In het bovenstaande is getracht een beeld te geven van de huidige situatie rond het Nederlands Historisch Instituut te Rome en van mogelijkheden voor deze rijksinstellling in de toekomst. Deze poging moge een bijdrage zijn in de algemene discussie, momenteel gevoerd, om te komen tot een verbreding en intensivering van de beoefening van de geschiedwetenschap in Nederland. 


\section{Recensies}

\section{ALGEMEEN}

Geschiedenis van Overijssel, onder redactie van B. H. SLICHER VAN BATH, G. D. VAN DER HEIDE, e.a. (Deventer; 1970, 418 blz., Kluwer).

De belangstelling van de meeste auteurs die aan deze prachtig uitgevoerde Geschiedenis van Overijssel hebben meegewerkt gaat niet uitsluitend naar de geschiedenis van deze provincie uit al bezitten ze allen ten aanzien van Overijssel een op eigen onderzoekingen gebaseerde deskundigheid. Dat is een gelukkige omstandigheid: daardoor immers wordt het gevaar van een al te beperkte kijk op de gebeurtenissen en ontwikkelingen in principe bezworen. Het is een boek voor liefhebbers - een wetenschappelijke annotatie ontbreekt geschreven door vaklieden op velerlei gebied. Zij geven deels samenvattingen van oudere studies - al dan niet van eigen hand - deels het resultaat van nieuw onderzoek. Het werk opent met een uitvoerig hoofdstuk van Th. van der Hammen en G. C. Maarleveld over de bodemvorming in het gewest, een wat hachelijk begin omdat dit onderwerp zich ook nu weer slecht blijkt te lenen tot voor een algemeen publiek begrijpelijk proza. De lezer die toch enig inzicht wil krijgen in de ontwikkeling van het landschap en de bodemgesteldheid kan veel van zijn gading vinden in de bijdrage over pre- en protohistorie van C. C. W. J. Hijszeler, die deze zaken in kort bestek eenvoudig behandelt en voorts de sporen van menselijke bewoning nagaat. De politieke geschiedenis werd aan drie medewerkers (W. J. Alberts, W. J. Formsma en C. N. Fehrmann) toevertrouwd. Formsma, die Opstand en Republiek behandelt, slaagde er het beste in zijn stof tot een evenwichtig artikel te verwerken en de aandacht van de lezer geheel op de belangrijke momenten te richten. Slicher van Bath nam de sociale en economische geschiedenis voor zijn rekening met uitzondering van de industriële ontwikkeling sinds ca. 1800, die A. L. van Schelven beschrijft. In een uiteenzetting over de wankele basis van de Overijsselse welvaart in de middeleeuwen plaatst Slicher de ontwikkeling binnen het gewest uitdrukkelijk in haar algemeen-Westeuropese verband en wijst hij er op dat het niet aangaat haar slechts in het kader van een' Overijssels-Duitse regio te bestuderen. In een later hoofdstuk maakt de auteur de lezer vertrouwd met de voornaamste resultaten van zijn grote onderzoek naar de Overijsselse maatschappij en economie tijdens de Republiek. G. J. ter Kuile beschrijft de 'rechtskundige verschijnselen' tot ca. 1795; hij vat zijn taak breed op en behandelt zowel publiekrechtelijke als civielrechtelijke aangelegenheden. Het is dan ook eigenlijk vreemd dat hij de stedelijke instellingen en de waterstaat aan anderen moest overlaten. De eerste krijgen een afzonderlijke bespreking toebedeeld van de hand van K. de Vries, de waterschappen enkele bladzijden, nagelaten door Fockema Andreae. Krachtiger dan deze laatste is het eveneens posthume artikel van Post over kerkelijk leven in de middeleeuwen al geeft het vanzelfsprekend evenmin nieuwe inzichten. A. C. F. Koch en O. de 